Journal of Patient-Centered

\title{
Assessing the Patient-Perceived Monetary Value of Patient- Reported Outcome Improvement for Patients With Chronic Knee Conditions
}

\author{
Sarah B. Floyd \\ Alicia Oostdyk \\ Melanie Cozad \\ John M. Brooks \\ Paul Siffri \\ Brian Burnikel
}

Follow this and additional works at: https://aah.org/jpcrr

Part of the Health Economics Commons, Health Services Research Commons, Musculoskeletal Diseases Commons, and the Orthopedics Commons

\section{Recommended Citation}

Floyd SB, Oostdyk A, Cozad M, Brooks JM, Siffri P, Burnikel B. Assessing the patient-perceived monetary value of patient-reported outcome improvement for patients with chronic knee conditions. J Patient Cent Res Rev. 2021;8:98-106. doi: 10.17294/2330-0698.1803

Published quarterly by Midwest-based health system Advocate Aurora Health and indexed in PubMed Central, the Journal of Patient-Centered Research and Reviews (JPCRR) is an open access, peer-reviewed medical journal focused on disseminating scholarly works devoted to improving patient-centered care practices, health outcomes, and the patient experience. 


\title{
Assessing the Patient-Perceived Monetary Value of Patient-Reported Outcome Improvement for Patients With Chronic Knee Conditions
}

\author{
Sarah B. Floyd, PhD, , ${ }^{1,2}$ Alicia Oostdyk, MPH, ${ }^{2,3}$ Melanie Cozad, PhD, ${ }^{2,3}$ John M. Brooks, PhD, ${ }^{2,3}$ \\ Paul Siffri, MD, ${ }^{4}$ Brian Burnikel, MD ${ }^{4}$ \\ ${ }^{1}$ Department of Public Health Sciences, Clemson University, Clemson, SC; ${ }^{2}$ Center for Effectiveness Research in \\ Orthopaedics, Columbia, SC; ${ }^{3}$ Department of Health Services Policy and Management, University of South Carolina, \\ Columbia, SC; ${ }^{4}$ Steadman Hawkins Clinic of the Carolinas, Prisma Health-Upstate, Greenville, SC
}

\begin{abstract}
Purpose
The high cost of orthopaedic care has attracted criticism in the current value-based health care environment. The objective of this work was to assess the properties of a willingness to pay (WTP)based approach to estimate the monetary value that patients place on health improvements in chronic knee conditions following orthopaedic treatment.

Methods A sample of patients with a chronic knee condition were surveyed between January and May of 2018 at a large orthopaedic practice. Each patient provided their WTP for restoration to ideal knee health and completed the Single Assessment Numerical Evaluation (SANE) to describe their baseline knee state. Average WTP was calculated for the total sample and stratified by income, age, and baseline SANE (for which 0 is the worst and 100 is the best) levels. The patient-perceived monetary value of each unit of SANE improvement was assessed.
\end{abstract}

Results $\quad$ The study sample included 86 patients seeking orthopaedic care for a chronic knee condition. Mean baseline SANE score was 45.5 (standard deviation: 25.0). Mean WTP to obtain ideal knee function from baseline was $\$ 18,704$ (standard deviation: $\$ 18,040$ ). For the full sample, patients valued a 1-unit improvement in SANE score at $\$ 291.1$ ( $\beta$ : 291.1; $P<0.05)$. The amount of money patients were willing to pay to achieve ideal knee function varied with age, income, and baseline knee state.

Conclusions Patients appear to highly value improvement in chronic knee conditions. Willingness-to-pay survey results appear to track expected variation in patient outcome valuation by income and baseline knee condition and could be a valuable approach to assess value-based care in orthopaedics. (J Patient Cent Res Rev. 2021;8:98-106.)

Keywords $\quad$ knee conditions; outcome measures; questionnaire; value of care; willingness to pay; orthopaedics

$\mathrm{T}$ The primary goal of orthopaedic medicine is to restore mobility and function and reduce pain from musculoskeletal conditions so that patients can work, play, and participate in the activities they enjoy. Although many orthopaedic treatments are widely considered successful and allow patients to resume active, healthy lifestyles, ${ }^{1-3}$ orthopaedic care is expensive and has attracted criticism in the current value-based health care environment. ${ }^{4-6}$ As the cost of orthopaedic care continues to rise, achieving value-based care in orthopaedics is

Corresponding author: Sarah B. Floyd, PhD,

Department of Public Health Sciences, Clemson University,

605 Grove Road, Greenville, SC 29605 (SBF@clemson.edu) a priority for all stakeholders..$^{5-8}$ The full valuation of orthopaedic care requires estimates of both the costs of treatment and the monetary value patients place on the outcome improvement gained from treatment. ${ }^{9}$ The criticisms surrounding the high cost of orthopaedic care have been difficult to rebuff because it is easier to estimate the costs associated with orthopaedic care than determine the monetary value patients place on outcome improvement gained from treatment. ${ }^{9,10}$

Patient-reported outcome measures (PROMs) are commonly used tools in orthopaedic medicine to measure health outcome changes. ${ }^{11,12}$ However, PROM scores do not directly yield measures of monetary value because it is unknown how much patients value PROM score improvement. Contingent valuation is a standard surveybased approach used in environmental assessment that 
has more recently been used to measure willingness to pay (WTP) for health improvements. ${ }^{13-15}$

The WTP literature in health care has grown over the past few decades, with applications in many different disease areas and treatment modalities. ${ }^{16-19}$ WTP studies in orthopaedics have focused on estimating how much patients are willing to pay for specific diagnostic tests or treatments, such as total joint replacement. ${ }^{20-24}$ However, none of the existing WTP studies in orthopaedic medicine aim to estimate the patient-perceived monetary value associated with PROM improvement following treatment.

In this study we developed a novel contingent valuation survey approach to elicit the monetary value patients place on knee improvement. We assessed the validity of our approach by testing whether WTP responses vary with income, age, and baseline knee state, as we hypothesized they should. ${ }^{25}$ The monetary value patients report they would be willing to pay to achieve ideal knee health was elicited, and the monetary value per unit improvement in the Single Assessment Numeric Evaluation (SANE), a widely accepted PROM, was evaluated. Estimating the patient-perceived economic value of PROM improvement allows for future costbenefit assessments of orthopaedic procedures and may enhance our understanding of whether we are delivering value-based care in orthopaedics.

\section{METHODS}

\section{Survey Development and Pilot Testing}

A pilot version of the WTP survey was evaluated in two steps prior to study enrollment. First, the survey instrument was piloted with 15 orthopaedic patients with knee disability who were not included in the final study sample. Patients were guided through the survey in a face-to-face format by a member of the research team, then a qualitative interview was conducted following the survey. During the qualitative interview, the research team probed patients about the difficulty conceptualizing ideal knee health and answering the WTP question, in addition to overall survey length and clarity. Patients were compensated with a $\$ 30$ gift card for completing the survey and qualitative interview.

The survey also was presented to the Patient Engagement Studio affiliated with the health system where this work was performed..$^{26}$ Patient investigators at the studio were asked to refine the wording used in the WTP question and provide revisions to the near-final survey. Responses from the qualitative interviews and Patient Engagement Studio meeting were summarized and used to develop the final version of the WTP survey tool.

\section{Sampling and Recruitment}

This study was approved by the institutional review board at the regional health system (Prisma Health-Upstate) where this work was performed. Eligible patients were identified from the clinical population of an orthopaedic practice within a large regional health system between January and May of 2018. The clinical schedules of 2 orthopaedic surgeons were screened for eligible patients. Patients were considered to be eligible if they were 1) over the age of 18 , 2) were being seen by the doctor for a chief knee complaint of pain or functional limitation, 3) had not received knee surgery in the past year, and 4) reported a knee condition that was present for more than 9 months. Consultation with clinical collaborators indicated that a condition that had not resolved after 9 months should be deemed chronic. Patients experiencing chronic knee conditions were felt to be best suited to reflect on the longstanding pain and functional limitations of their condition and ultimately evaluate the monetary value of knee improvement.

After checking in for their appointment with clinic staff, eligible patients were approached as they waited for their orthopaedic visit and were invited to participate in the study. Participation in the survey included answering a face-to-face survey administered via an iPad using the online open-source platform Lime Survey (www. limesurvey.org/). Patients were presented with the aim and scope of the study and reassured about the confidentiality and anonymity of their answers. They were told that the survey would last 5 to 10 minutes. Patients were compensated with a $\$ 10$ gift card for completing the survey. Patients provided their consent to participate in this study by completing an online informed consent document.

The research team identified 385 individuals as potentially eligible for the study. Of those, 110 were approached to participate and 100 of those agreed to participate. A total of 87 patients reported experiencing a chronic condition and were included in the study; 13 patients reported acute conditions and were excluded from the study. WTP responses that appeared implausible in relation to household income were evaluated. One observation was deemed an implausible outlier - the patient provided a WTP value that was more than 7 times higher than the patient's household income - and was excluded from the analysis. Thus, the final study sample included 86 patients with chronic knee conditions.

\section{Evaluation of Willingness to Pay}

Standard bidding game and payment card formats were adapted to assess how much patients valued hypothetical improvements in knee health. ${ }^{15}$ The WTP question introduction assured patients that their individual answers 
would not be used to set prices for orthopaedic services and would not be shared with their physician or health system. The WTP question asked patients to consider the existence of a hypothetical treatment that would restore their knee to ideal health and allow them to do all the activities they wanted to do without thinking about it. However, insurance would not cover the cost of the treatment so if the patient wanted it, they had to pay for it on their own.

The WTP response options were structured like a car payment, in that patients were presented with a bid and asked if they would pay that amount of money on a monthly basis for 5 years. This helped accommodate the fact that payments for knee health are large sums of money that many patients would find difficult to pay in one lump sum. Patients were presented with a starting monthly bid of $\$ 100$ and asked to answer "yes" or "no" to that bid amount. From there, the bid amount was raised or lowered according to the patients' answer until the maximum monthly bid was reached. If a patient responded "no" to a given bid amount, subsequent bids were reduced by $\$ 25$. The monthly payment response options ranged from $\$ 0$ to $\$ 1950$ per month and increased by $\$ 100$ increments after a subsequent answer of "yes." An open response was used if a patient indicated they would pay more than $\$ 1950 /$ month. For each payment amount, the monthly payment and total investment amount across 5 years were presented to the patient.

\section{PROM Questionnaire}

To evaluate baseline knee state, patients were given the SANE, a standard PROM used across many joints in orthopaedics. ${ }^{27-31}$ Unlike other PROMs that are comprised of multiple domain subscales, the SANE consists of a single-item scale. ${ }^{32}$ The SANE asks patients a single question: "How would you rate your knee today as a percentage of normal (0\% to 100\% scale, with 100\% being normal)?" Patients can respond with a number between 0 and 100 . Using the SANE result, the PROM change needed to move from each patient's baseline SANE score to ideal knee health (ie, 100 - SANE score provided) was calculated. The psychometric properties of the SANE have been demonstrated for patients with shoulder conditions, ${ }^{33}$ and the SANE score has been shown to have moderate to strong positive correlations with the modified Cincinnati Knee Rating System and International Knee Documentation Committee subjective knee surveys. ${ }^{27}$

The survey obtained self-reported patient demographics, including age and household income.

\section{Data Analysis}

Patient demographics were summarized for the study sample. Each patient's total WTP was computed by multiplying their maximum monthly bid by 60 (12 months $\times 5$ years). Mean SANE and WTP scores were reported for all survey respondents and by predisposing factor, income, and perceived need as baseline SANE scores. Income levels included household income less than $\$ 25,000, \quad \$ 25,000-\$ 49,999, \quad \$ 50,000-\$ 74,999$, $\$ 75,000-\$ 99,999$, and greater than $\$ 100,000$. Age groups were classified as less than 55,55 to 64 , and 65 or greater years. Baseline SANE scores were categorized into quartiles (0-29, 30-49, 50-64, and 65 or higher).

The dependent variable was specified as the total WTP value, and the independent variable of interest was the PROM change needed to move from each patient's baseline SANE score to ideal knee health (ie, a SANE score of 100). For example, if a patient's baseline index SANE score was 55, a 45-unit SANE improvement (100 - 55) would be needed to obtain ideal knee health. The interpretation of coefficients was the patient-perceived monetary value of a 1-unit improvement in the SANE. Simple linear regression analysis was used to assess the relationship between SANE change and WTP values. Interaction effects were used to assess coefficients by income, age, and SANE groups. We excluded the intercept from models because someone with zero SANE potential improvement (baseline SANE of 100) would not be willing to pay anything $(\$ 0)$.

All analyses were conducted using Stata ${ }^{\circledR} 15$ (StataCorp LLC) and SAS ${ }^{\circledR} 9.4$ (SAS Institute Inc.) statistical software.

\section{RESULTS \\ Patient Characteristics}

All 86 patients participating in the study completed the SANE and WTP questions; although, some patients declined to provide answers to demographic survey questions (85 responses with complete age information; 67 with complete income information). Most of the patient sample was female $(59.3 \%)$, married $(69.8 \%)$, and 65 years of age or older $(60.5 \%)$. Of the patient sample, $46.5 \%$ had a bachelor's degree or higher. The sample was mostly composed of patients who were not working, either due to unemployment $(4.6 \%)$ or retirement $(61.6 \%)$. The patient sample was financially diverse, with household incomes ranging from less than $\$ 25,000$ to greater than $\$ 100,000 ; 52 \%$ reported having a household income of greater than $\$ 50,000$. Complete sample characteristics are provided in Table 1.

\section{Willingness to Pay for Knee Health}

All survey respondents indicated that they would pay some amount of money to achieve ideal knee health. The range of monthly WTP bids was $\$ 25$ to $\$ 2000$, with the mean monthly WTP value being $\$ 311.7$ (standard 
Table 1. Population Characteristics and Baseline SANE Scores

\begin{tabular}{|c|c|c|c|}
\hline Characteristic & n (\%) & Maximum WTP, Mean (SD) & $P$ \\
\hline Study sample & $86(100 \%)$ & $\$ 18,704(18,040)$ & \\
\hline Sex & & & 0.91 \\
\hline Male & $35(40.7)$ & $\$ 17,628(14,717)$ & \\
\hline Female & $51(59.3)$ & $\$ 19,442(20,116)$ & \\
\hline Age & & & 0.29 \\
\hline$<55$ years & $7(8.1)$ & $\$ 12,535(8,269)$ & \\
\hline $55-64$ years & $26(30.2)$ & $\$ 21,219(23,467)$ & \\
\hline$\geq 65$ years & $52(60.5)$ & $\$ 17,468(14,825)$ & \\
\hline Declined to answer & $1(1.2)$ & $\$ 60,750$ & \\
\hline Education & & & 0.02 \\
\hline Less than high school diploma & $5(5.8)$ & $\$ 13,200(14,779)$ & \\
\hline High school diploma & $12(13.9)$ & $\$ 12,192(9,104)$ & \\
\hline Some college & $18(20.9)$ & $\$ 12,916(7,637)$ & \\
\hline Associates degree & $11(12.8)$ & $\$ 11,113(6,937)$ & \\
\hline Bachelor's degree & $22(25.6)$ & $\$ 24,477(25,726)$ & \\
\hline Master's or doctorate degree & $18(20.9)$ & $\$ 27,945(19,312)$ & \\
\hline Marital status & & & 0.55 \\
\hline Single & $4(4.6)$ & $\$ 37,500(55,449)$ & \\
\hline Married & $60(69.8)$ & $\$ 18,859(14,712)$ & \\
\hline Widowed & $9(10.5)$ & $\$ 14,416(9,160)$ & \\
\hline Divorced & $13(15.1)$ & $\$ 15,173(16,474)$ & \\
\hline Annual income & & & 0.02 \\
\hline$<\$ 25,000$ & $6(7.0)$ & $\$ 8,375(6,664)$ & \\
\hline$\$ 25,000$ to $\$ 49,999$ & $16(18.6)$ & $\$ 14,253(11,561)$ & \\
\hline$\$ 50,000$ to $\$ 74,999$ & $15(17.4)$ & $\$ 13,930(7,596)$ & \\
\hline$\$ 75,000$ to $\$ 99,999$ & $11(12.8)$ & $\$ 22,090(16,552)$ & \\
\hline$\geq \$ 100,000$ & $19(22.1)$ & $\$ 31,740(28,133)$ & \\
\hline Declined to answer & $19(22.1)$ & $\$ 14,487(12,137)$ & \\
\hline Employment status & & & 0.71 \\
\hline Unemployed & $4(4.6)$ & $\$ 13,875(3,750)$ & \\
\hline Employed, part-time & $7(8.1)$ & $\$ 19,821(13,521)$ & \\
\hline Employed, full-time & $21(24.4)$ & $\$ 19,057(24,606)$ & \\
\hline Retired & $53(61.6)$ & $\$ 19,049(16,470)$ & \\
\hline Declined to answer & $1(1.2)$ & $\$ 4,500$ & \\
\hline Baseline SANE score, mean \pm SD & $45.5 \pm 25.0$ & & 0.97 \\
\hline $0-29(n=19)$ & $9.0 \pm 8.7$ & $\$ 18,283(13,456)$ & \\
\hline $30-49(n=19)$ & $36.3 \pm 5.2$ & $\$ 21,118(21,684)$ & \\
\hline $50-64(n=26)$ & $52.3 \pm 4.3$ & $\$ 19,200(22,905)$ & \\
\hline $65-100(n=22)$ & $76.8 \pm 7.2$ & $\$ 16,398(11,100)$ & \\
\hline
\end{tabular}

SANE, Single Assessment Numeric Evaluation; SD, standard deviation; WTP, willingness to pay.

Shapiro-Wilk was used to test for normality of maximum WTP. Kruskal-Wallis was used to test for differences in mean WTP, with statistical significance defined as $P<0.05$.

deviation: 300.7$)$. The range of total WTP responses was $\$ 1500$ to $\$ 120,000$, with the mean total WTP value of $\$ 18,704$ (standard deviation: 18,040). Nearly $40 \%$ of the sample reported that they would be willing to pay in the range of $\$ 10,000-\$ 24,999$, while $38 \%$ of the sample reported they would be willing to pay less than $\$ 10,000$. The distribution and frequencies of maximum WTP values are presented in Figure 1. 


\section{Willingness to Pay Stratified by Income Levels}

Among the 67 patients who reported household income, WTP amounts varied across income levels. As expected, there was an increasing trend in the amount of money patients would be willing to pay as household income levels rose from less than $\$ 25,000$ to greater than $\$ 100,000$. Patients reporting household income greater than $\$ 100,000$ were willing to pay the most for ideal knee health, at a mean total WTP of $\$ 31,740$. The value of a 1-unit SANE improvement increased with household income. Lower income patients were only willing to pay an average of $\$ 114.7$ per unit of SANE improvement, whereas patients with income greater than $\$ 100,000$ were willing to pay $\$ 577.4$ per unit of SANE improvement ( $\beta$ : $577.4 ; \mathrm{P}<0.05$ ). Total WTP for perfect knee health and WTP per unit of SANE improvement stratified by income are displayed in Figure 2.

\section{Willingness to Pay Stratified by Age Group}

Among the 85 patients who reported complete age information, WTP for perfect knee health varied across age groups. Patients less than 55 years old and 65 years old or older were willing to pay less for ideal knee health compared to patients between 55 and 64 years of age. Patients in the middle age group (55-64 years) were willing to pay $\$ 21,219$, on average, to achieve ideal knee health and $\$ 358.8$ per unit of SANE improvement ( $\beta$ : $358.8 ; \mathrm{P}<0.05$ ). Figure 3 shows WTP for perfect knee health stratified by age group.

\section{Willingness to Pay Stratified by Baseline SANE Level}

Across the entire sample of 86 patients, those with lower baseline SANE scores (higher perceived need) were willing to pay more than those with higher baseline SANE scores (lower perceived need). On average, patients with a baseline SANE score between 0 and 29 were willing to pay $\$ 18,283$ to have their knee restored to ideal health. Patients with a baseline SANE score between 65 and 90 were willing to pay $\$ 16,398$ to have their knee restored to ideal health. Using regression analysis, a 1-unit increase in SANE score was worth $\$ 291.1(\beta: 291.1 ; \mathrm{P}<0.05)$ to patients. Maximum WTP stratified by baseline SANE is presented in Figure 4.

\section{DISCUSSION}

This study assessed the ability of a contingent valuation survey to understand how much patients are willing to pay for hypothetical improvements in chronic knee conditions. A push is happening in orthopaedics to measure patient outcomes using PROMs, ${ }^{11,34}$ but PROMs in and of themselves do not provide a monetary value on the health improvements patients receive from orthopaedic interventions. Our study is the first to apply contingent valuation survey methods to directly estimate the monetary value patients place on outcome improvement.

Using contingent valuation, we were able to estimate how much patients with chronic knee conditions would be willing to pay for improved knee health. The validity of this approach was supported by the fact that our results varied with predisposing and need factors that we anticipated would affect the value of patient-perceived outcome improvement. We found a positive relationship between household income and what patients are willing to pay for improvement in their knee condition.

On average, patients reported that they would be willing to pay $\$ 18,704$ to improve 54.5 SANE points to achieve restoration to ideal knee health, which suggests that outcomes achieved via orthopaedic intervention are highly valuable to patients. Across the sample, a 1-unit improvement in SANE scores was associated with a \$291 monetary value. Patients with baseline SANE scores between 30 and 49 were willing to pay the highest monetary value for a hypothetical treatment that would restore their knee to perfect health. This relationship was not clear for patients starting with the lowest SANE scores, which we suspect shows the need for contingent valuation methods to be applied in larger samples than we used herein.

Previous valuation studies in orthopaedics have not measured value gains against a PROM scale and instead estimated patients' WTP for distinct diagnostic tests or treatments. ${ }^{4,16,18-23,35-39}$ For example, Bozic et al found that patients were willing to pay $\$ 69,419$, on average, for hip arthroplasty. ${ }^{20}$ Similarly, Hall et al found that patients were willing to pay $\$ 4867$, on average, for an anterior cruciate ligament reconstruction. ${ }^{23}$ Although previous economic evaluations in orthopaedics demonstrate the value patients place on distinct treatments and diagnostic tools, our objective was to find a more general approach by assessing the value of health improvements as measured with a commonly used and accepted PROM. We believe this is the first to attempt to estimate these relationships directly. This general approach can be applied to PROM changes associated with individual treatments. The SANE score is a holistic PROM that does not rely on specific symptom dimensions and therefore may reflect the primary symptom dimensions that are most important to each patient. Furthermore, the SANE is widely applicable across diverse musculoskeletal conditions. ${ }^{27,29,40,41}$

With a hyperfocus on delivering value-based care, our results can inform stakeholders of the patient-perceived value of PROM changes associated with orthopaedic interventions. Our work provides preliminary estimates 


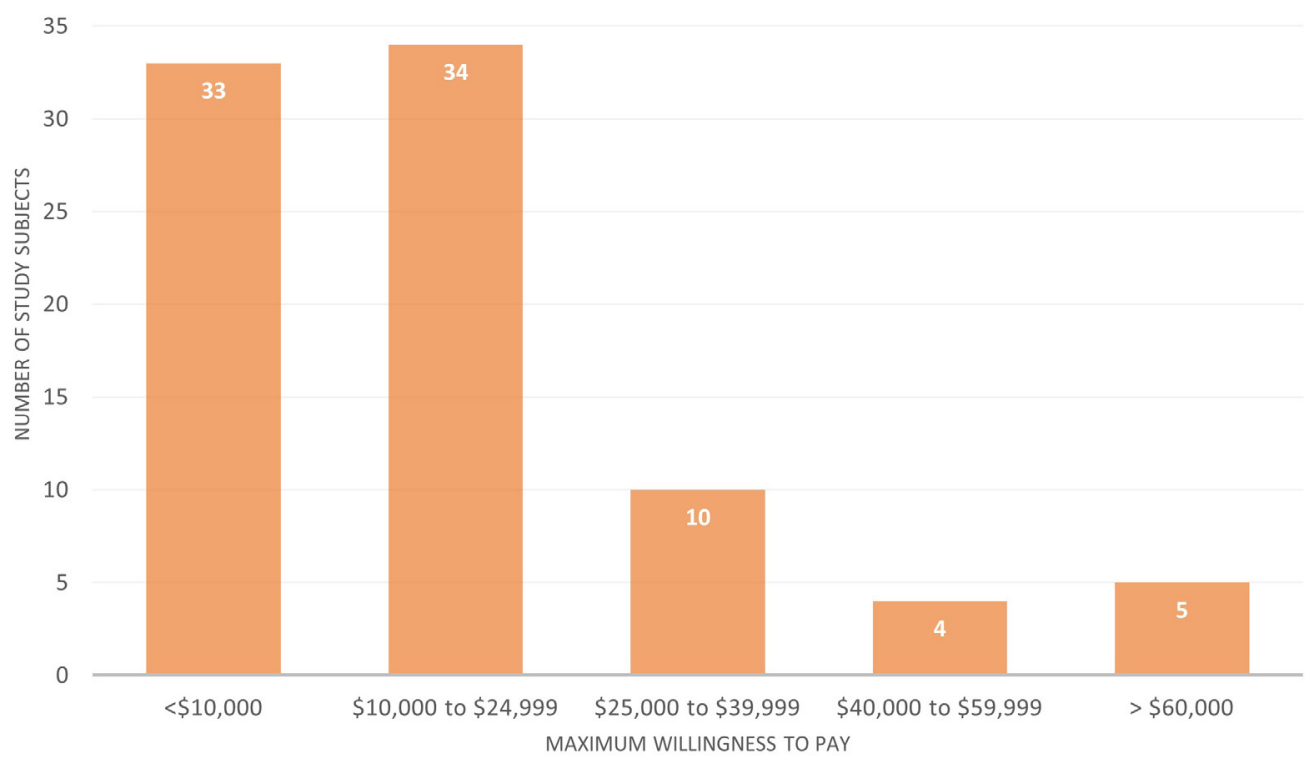

Figure 1. Distribution of maximum willingness to pay amounts.

$\$ 35,000$

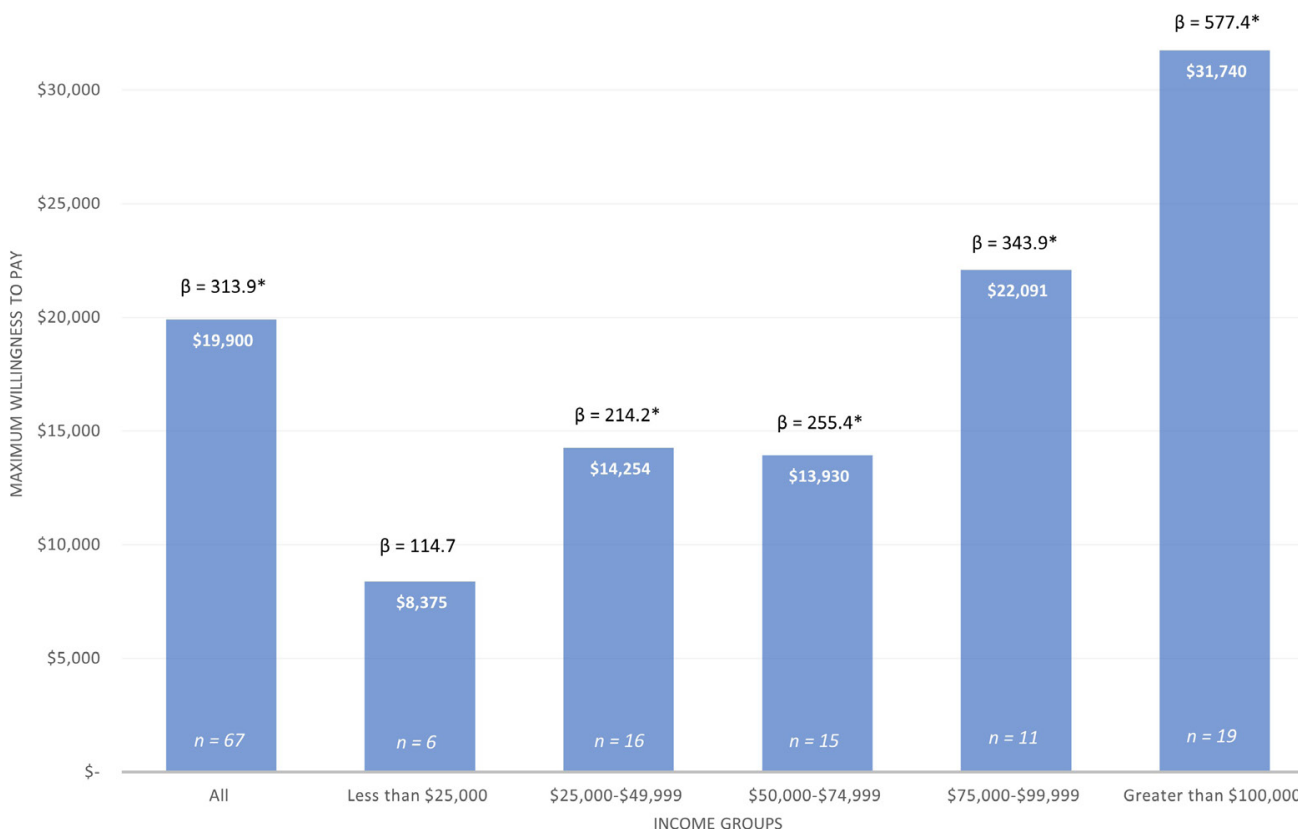

Figure 2. Willingness to pay stratified by income levels. Asterisks $\left(^{*}\right)$ indicate statistically significant beta of $P<0.05$.

of the monetary value of a 1-unit change in one of these PROMs - SANE score. For example, if a given knee treatment has been found to increase SANE scores by an average of 20 points, our estimates suggest the average patient will value this improvement at $\$ 5822$ $(20 \times 291.1)$. Therefore, these results can be applied to economic evaluations, such as cost-benefit analyses in orthopaedics, to inform the value-based narrative in this medical specialty.

\section{Limitations}

While we showed the potential of using contingent valuation methods to link PROM score changes to patient monetary valuation, the study had limitations that should make researchers cautious to directly apply its results. Foremost, our final analysis included a relatively small sample of individuals $(\mathrm{n}=86)$ and is only reflective of patients from one regional health system in the southeastern United States with one general joint complaint. As such, results were at the mercy of wide 
variation and outliers. We could not fully assess any variation in WTP across patient groups, and our point estimates in this study for any single patient characteristic should not be relied on for forecasting. The range of total WTP responses was $\$ 1500$ to $\$ 120,000$, with the mean total WTP value of $\$ 18,704$. WTP estimates generally varied across individual patient characteristics as we anticipated, however, we believe this approach can only provide valid estimates of value individual patients place on health improvements using a larger sample size.

Furthermore, there are several known limitations to the use of WTP assessments with hypothetical outcomes.
However, the concept of monthly out-of-pocket costs for treatment was deployed to ease the burden of the WTP question, and the pilot testing process was used to improve survey language and clarity. As noted in the Methods section, patients on an engagement panel reviewed the WTP language and provided patient perspectives on how best to word the final survey question. While results suggest that WTP may be a feasible approach to inform the discussion surrounding value-based care in orthopaedic medicine, future WTP analysis based on larger samples of orthopaedic patients and with more robust model approaches to adjust for potential interactions is warranted.

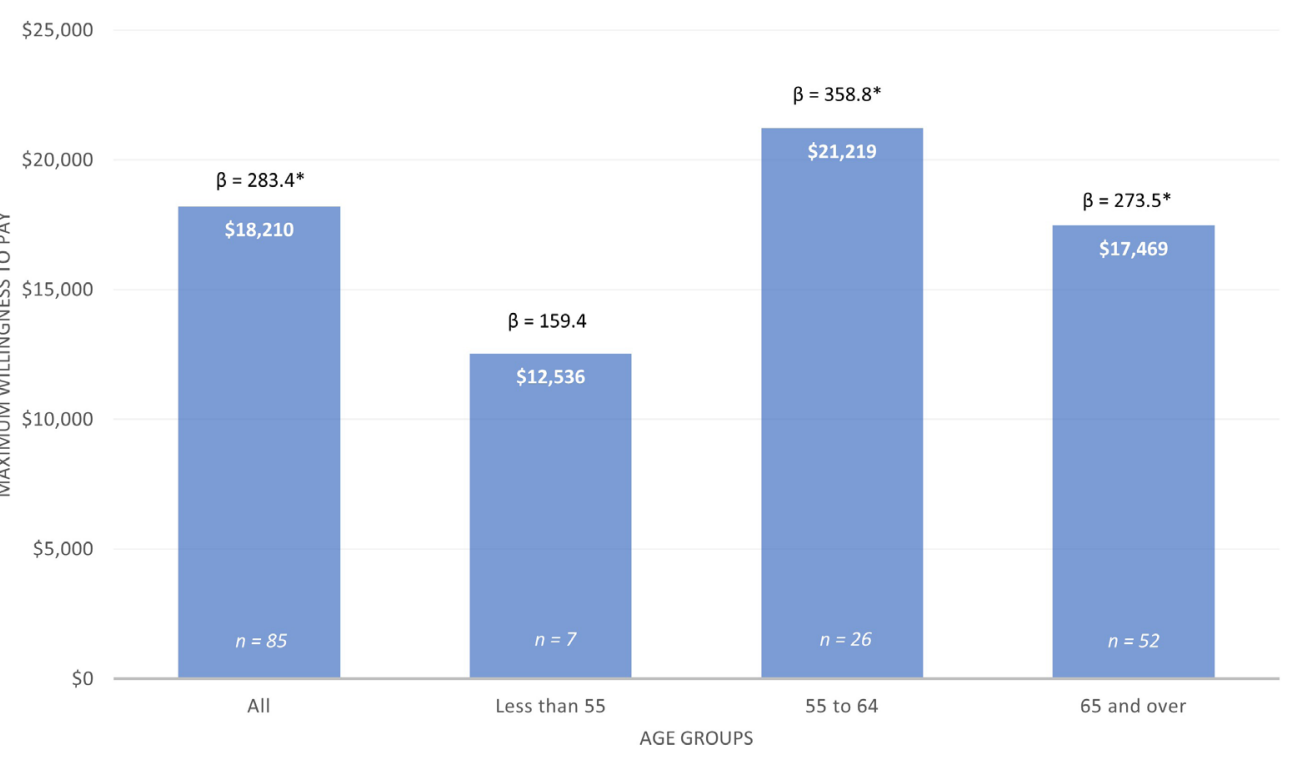

$\$ 25,000$

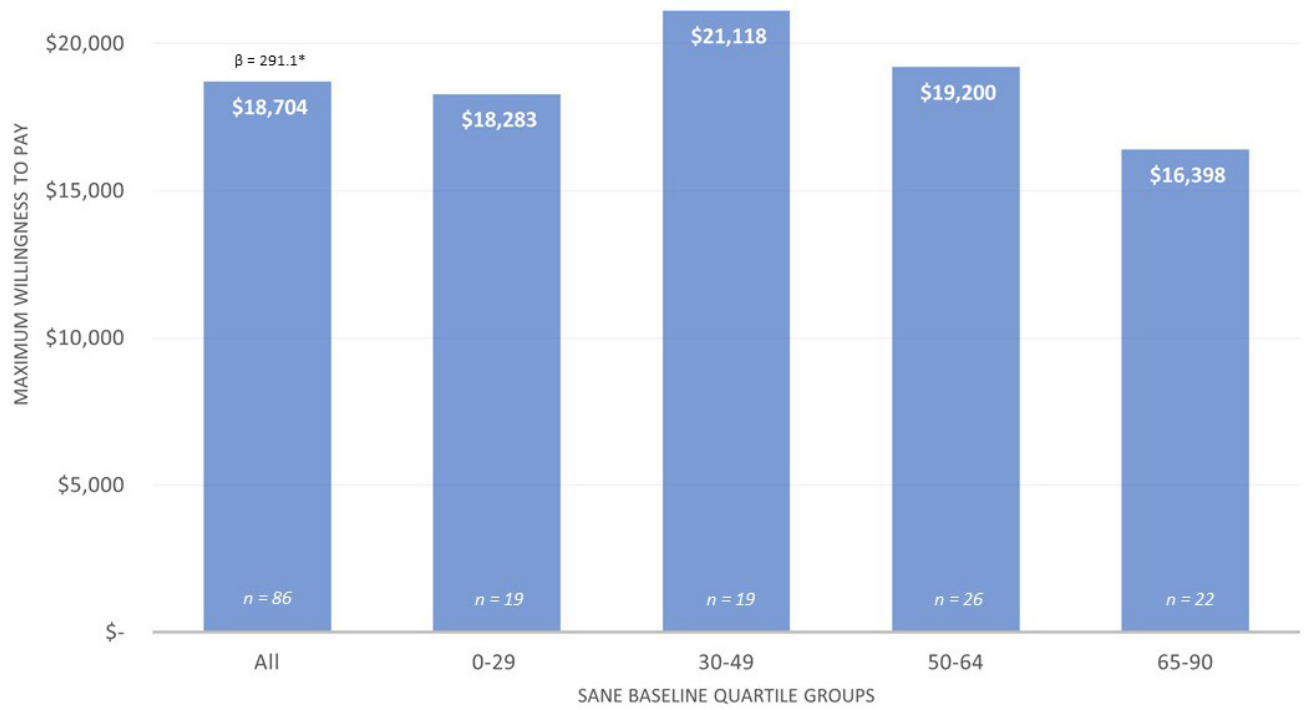

Figure 3. Willingness to pay stratified by age groups. Asterisks (*) indicate statistically significant beta of $P<0.05$.
Figure 4. Willingness to pay stratified by baseline Single Assessment Numeric Evaluation (SANE) level. 


\section{CONCLUSIONS}

Measuring the value associated with improvements from patient-reported outcome measures is an important step toward providing important insights about the benefits of knee health to patients and the holistic value of orthopaedic medicine. While this study was small and exploratory, it demonstrates that contingent valuation survey methods assessing the benefits associated with outcome improvement can provide important information to support value-based decision-making in orthopaedic care.

\section{Patient-Friendly Recap}

- Orthopaedic procedures are often costly but can greatly improve quality of life for people with painful musculoskeletal conditions.

- Authors surveyed 86 patients with chronic knee pain or dysfunction to determine how much they would value, in monetary terms, a hypothetical treatment that restored their knee health.

- Patients were willing to pay an average of $\$ 18,704$ to improve the average baseline knee state to ideal function, with each 1-unit improvement in knee score valued at $\$ 291$.

- Degree of willingness to pay for knee health varied with age, income, and baseline status.

\section{Author Contributions}

Study design: Floyd, Oostdyk, Cozad, Brooks. Data acquisition or analysis: all authors. Manuscript drafting: all authors. Critical revision: all authors.

\section{Conflicts of Interest}

None.

\section{References}

1. Moran CG, Horton TC. Total knee replacement: the joint of the decade. BMJ. 2000;320(7328):820. CrossRef

2. Learmonth ID, Young C, Rorabeck C. The operation of the century: total hip replacement. Lancet. 2007;370:1508-19. CrossRef

3. Ayers DC, Franklin PD, Ring DC. The role of emotional health in functional outcomes after orthopaedic surgery: extending the biopsychosocial model to orthopaedics. $J$ Bone Joint Surg Am. 2013;95(21):e165. CrossRef

4. Bumpass DB, Nunley RM. Assessing the value of a total joint replacement. Curr Rev Musculoskelet Med. 2012;5:274-82. CrossRef

5. Bozic KJ. Value-based healthcare and orthopaedic surgery. Clin Orthop Relat Res. 2012;470:1004-5. CrossRef

6. Bozic KJ. What's important: preparing for the transition to value-based health care: an American Orthopaedic Association (AOA) 2016 OrthoTalk. J Bone Joint Surg Am. 2017;99:1150-2. CrossRef
7. Attarian DE, Seyler TM, Bolognesi MP. Overview: valuebased care for orthopedic surgery. Tech Orthop. 2020;35(1):3-6.

8. Jamgochian G, Abboud J, Churchill R, et al. The value of shoulder replacement and rotator cuff surgery: the patients' perspective. J Shoulder Elbow Surg. 2019;28:e339-43. CrossRef

9. Porter ME. What is value in health care? $N$ Engl J Med. 2010;363:2477-81. CrossRef

10. Wei DH, Hawker GA, Jevsevar DS, Bozic KJ. Improving value in musculoskeletal care delivery. J Bone Joint Surg Am. 2015;97:769-74. CrossRef

11. Siljander MP, McQuivey KS, Fahs AM, Galasso LA, Serdahely KJ, Karadsheh MS. Current trends in patient-reported outcome measures in total joint arthroplasty: a study of 4 major orthopaedic journals. J Arthroplasty. 2018;33:3416-21. CrossRef

12. Gagnier JJ. Patient reported outcomes in orthopaedics. J Orthop Res. 2017;35:2098-108. CrossRef

13. Klose T. The contingent valuation method in health care. Health Policy. 1999;47:97-123. CrossRef

14. Bala MV, Wood LL, Zarkin GA, Norton EC, Gafni A, O'Brien, B. Valuing outcomes in health care: a comparison of willingness to pay and quality-adjusted life-years. J Clin Epidemiol. 1998;51:667-76. CrossRef

15. Mitchell RC, Carson RT. Using Surveys to Value Public Goods: The Contingent Valuation Method. Resources for the Future; 1989.

16. Burnett HF, Ungar WJ, Regier DA, Feldman BM, Miller FA. Parents' willingness to pay for biologic treatments in juvenile idiopathic arthritis. Value Health. 2014;17:830-7. CrossRef

17. Neumann PJ, Cohen JT, Hammitt JK, et al. Willingness-to-pay for predictive tests with no immediate treatment implications: a survey of US residents. Health Econ. 2012;21:238-51. CrossRef

18. Fautrel B, Clarke AE., Guillemin F, et al. Valuing a hypothetical cure for rheumatoid arthritis using the contingent valuation methodology: the patient perspective. J Rheumatol. 2005;32:443-53.

19. Lin PJ, Cangelosi MJ, Lee DW, Neumann PJ. Willingness to pay for diagnostic technologies: a review of the contingent valuation literature. Value Health. 2013;16:797-805. CrossRef

20. Bozic KJ, Chiu V, Slover JD, Immerman I, Kahn JG. Patient preferences and willingness to pay for arthroplasty surgery in patients with osteoarthritis of the hip. J Arthroplasty. 2012;27:503-6.e2. CrossRef

21. Posnett J, Dixit S, Oppenheimer B, Kili S, Mehin N. Patient preference and willingness to pay for knee osteoarthritis treatments. Patient Prefer Adherence. 2015;9:733-44. CrossRef

22. Cross MJ, March LM, Lapsley HM, et al. Determinants of willingness to pay for hip and knee joint replacement surgery for osteoarthritis. Rheumatology (Oxford). 2000;39:1242-8. CrossRef

23. Hall MP, Chiang-Colvin AS, Bosco JA 3rd. Willingness to pay for anterior cruciate ligament reconstruction. Bull Hosp Jt Dis (2013). 2013;7:218-21.

24. Courtney PM, Howard M, Goyal N, Schwarzkopf R, Schnaser E, Sheth NP. How much do patients value total hip and knee arthroplasty? A prospective, multicenter study. J Arthroplasty. 2016;31:562-6.e3. CrossRef

25. Andersen RM. Revisiting the behavioral model and access to medical care: Does it matter? J Health Soc Behav. 1995;36:1-10. $\underline{\text { CrossRef }}$ 
26. Prisma Health. Patient Engagement Studio. Accessed January 19, 2017. http://university.ghs.org/pes/

27. Shelbourne KD, Barnes AF, Gray T. Correlation of a single assessment numeric evaluation (SANE) rating with modified Cincinnati knee rating system and IKDC subjective total scores for patients after ACL reconstruction or knee arthroscopy. Am J Sports Med. 2012;40:2487-91. CrossRef

28. Pietrosimone B, Luc BA, Duncan A, Saliba SA, Hart JM, Ingersoll $\mathrm{CD}$. Association between the single assessment numeric evaluation and the Western Ontario and McMaster Universities Osteoarthritis Index. J Athl Train. 2017;52:526-33. CrossRef

29. Winterstein AP, McGuine TA, Carr KE, Hetzel SJ. Comparison of IKDC and SANE outcome measures following knee injury in active female patients. Sports Health. Nov 2013;5:523-9. CrossRef

30. Cunningham G, Lädermann A, Denard PJ, Kherad O, Burkhart SS. Correlation between American shoulder and elbow surgeons and single assessment numerical evaluation score after rotator cuff or SLAP repair. Arthroscopy. 2015;31:1688-92. CrossRef

31. Thigpen CA, Shanley E, Momaya AM, et al. Validity and responsiveness of the single alpha-numeric evaluation for shoulder patients. Am J Sports Med. 2018;46:3480-5. CrossRef

32. Bellas N, Cirino C, Cote MP, Sathe V, Geaney L. Validation of the Single Assessment Numeric Evaluation (SANE) score as an outcome measure by comparison to the revised Foot Function Index (rFFI). (abstr.) Foot Ankle Orthop. 2019;4(3). CrossRef

33. Nazari G, MacDermid JC, Bobos P, Furtado R. Psychometric properties of the Single Assessment Numeric Evaluation (SANE) in patients with shoulder conditions. A systematic review. Physiotherapy. 2020;109:33-42. CrossRef

34. MOTION Group. Patient-reported outcomes in orthopaedics. J Bone Joint Surg Am. 2018;100:436-42. CrossRef
35. Byrne MM, O’Malley KJ, Suarez-Almazor ME. Ethnic differences in health preferences: analysis using willingnessto-pay. J Rheumatol. 2004;31:1811-8.

36. Haefeli M, Elfering A, McIntosh E, Gray A, Sukthankar A, Boos N. A cost-benefit analysis using contingent valuation techniques: a feasibility study in spinal surgery. Value Health. 2008;11:575-88. CrossRef

37. Xie F, Thumboo J, Fong KY, et al. A study on indirect and intangible costs for patients with knee osteoarthritis in Singapore. Value Health. 2008;11 Suppl 1:S84-90. CrossRef

38. Ethgen O, Tancredi A, Lejeune E, Kvasc A, Zegels B, Reginster JY. Do utility values and willingness to pay suitably reflect health outcome in hip and knee osteoarthritis? A comparative analysis with the WOMAC Index. J Rheumatol. 2003;30:2452-9.

39. Fuhrmann A, Batash R, Schwarzkopf R, Backstein D. Patient willingness to contribute to the cost of novel implants in total joint arthroplasty: the Canadian experience. Can J Surg. 2019;62:294-9. CrossRef

40. Gowd AK, Charles MD, Liu JN, et al. Single Assessment Numeric Evaluation (SANE) is a reliable metric to measure clinically significant improvements following shoulder arthroplasty. J Shoulder Elbow Surg. 2019;28:2238-46. CrossRef

41. Wickman JR, Lau BC, Scribani MB, Wittstein JR. Single Assessment Numeric Evaluation (SANE) correlates with American Shoulder and Elbow Surgeons score and Western Ontario Rotator Cuff index in patients undergoing arthroscopic rotator cuff repair. J Shoulder Elbow Surg. 2020;29:363-9. CrossRef

(C) 2021 Advocate Aurora Health, Inc. 